\title{
Variational Data Assimilation in the Mathematical Model of the Black Sea Dynamics
}

\author{
V. I. Agoshkov, V. P. Shutyaev, E. I. Parmuzin*, N. B. Zakharova, \\ T. O. Sheloput, N. R. Lezina
}

Marchuk Institute of Numerical Mathematics, Russian Academy of Sciences, Moscow, Russian Federation

* eparmuzin@gmail.com

Purpose. In order to simulate the sea hydrothermodynamics, the problem of variational assimilation of the sea surface temperature data is solved. The data assimilation permits to adjust the numerical model calculations to the measurement data obtained in the environment under study.

Methods and Results. The mathematical model of hydrothermodynamics of the Black and Azov seas, developed at the Institute of Numerical Mathematics of RAS and written in the sigma coordinate system, is considered. The distinctive feature of the model consists in applying the splitting method to physical processes and spatial coordinates that can significantly simplify the variational data assimilation algorithm. The problem of variational assimilation of the sea surface temperature data is formulated. A cost functional has been introduced; it includes the control function - heat flux at the sea upper boundary and satellite observations of the sea surface temperature. The necessary condition for the functional minimum is reformulated through the optimality system including the direct and adjoint problems, and the control condition. Using the variational assimilation of the satellite-derived observations, the algorithm for solving the stated problem was developed. It takes into account the observational errors' covariance matrix calculated based on the statistical characteristics of the sea surface temperature observational data. The algorithm implies a sequential solution of the optimality system in the iterative process with the specially selected iterative parameter. The results of numerical solution of this problem are represented by the example of the Black and Azov seas.

Conslusion. The results of numerical modeling with the observational data assimilation and without it are compared; efficiency of the observational data assimilation procedures is shown. Influence of the sea surface temperature assimilation upon the other system parameters is investigated. It is shown that when assimilating the sea surface temperature, only temperature in the upper layers is affected, whereas, provided that the depth is sufficient, the profile in the lower layers remains practically unchanged. The impact on the other system parameters is either minimal or not manifested at all.

Keywords: mathematical model, variational assimilation, numerical algorithm, observations, hydrothermodynamics, sea surface temperature.

Acknowledgements: The work was supported by the Russian Science Foundation project No. 19-7120035 (problem statement, algorithm development, numerical experiments) and the grant of the President of the Russian Federation No. MK-3228.2018.5 (processing of observation data and their preparation for model calculations).

For citation: Agoshkov, V.I., Shutyaev, V.P., Parmuzin, E.I, Zakharova, N.B., Sheloput, T.O. and Lezina, N.R., 2019. Variational Data Assimilation in the Mathematical Model of the Black Sea Dynamics. Physical Oceanography, [e-journal] 26(6), pp. 387-396. doi:10.22449/1573-160X-2019-6-515-527

DOI: $10.22449 / 1573-160 \mathrm{X}-2019-6-515-527$

(C) 2019, V. I. Agoshkov, V. P. Shutyaev, E. I. Parmuzin, N. B. Zakharova, T. O. Sheloput, N. R. Lezina (C) 2019, Physical Oceanography

\section{Introduction}

For reliable monitoring and forecasting of marine circulation, a data assimilation system should be created. One of its main components should be a physically complete and verified model that can be used to calculate water circulation. At the present stage of research, it is necessary to combine real data from 
observational systems and computational experiments of mathematical models, to increase the accuracy of modeling and prediction of physical processes. In recent years, data assimilation methods have been widely used in Earth sciences, providing the relationship between the two main components that permit monitoring of the environment state. These are observations and models. Such methods were most widely used in meteorology and oceanography, where observations are assimilated into numerical models in order to obtain boundary or initial conditions (or other model parameters) for further modeling and forecast [1-9].

The problems of variational data assimilation are formulated as optimal control problems [10-12]. As is known, when solving minimization problems, it becomes necessary to calculate the initial functional gradient. A major step in this direction was the use of the theory of adjoint equations. The development of this direction is largely based on the work of Academician G. I. Marchuk. In the 70s of $20^{\text {th }}$ century G. Marchuk formulated a fundamental approach to solving the problem of long-term weather forecast, based on the so-called adjoint equations for nonlinear models of hydrothermodynamics of the atmosphere and ocean [13]. Later, in the works of G. Marchuk, the theory of adjoint equations and disturbances algorithms was developed to study various classes of problems in mathematical physics [14]. It turned out to be fruitful for many other areas of science. As a result, more or less general approaches to the study of complex systems and mathematical models appeared [12]. These approaches were the main content of G. Marchuk multiannual research and his scientific school at the Institute of Numerical Mathematics (INM) of RAS in various fields of mathematics and its applications to diffusion problems, models of environmental protection, climate theory and its changes [13-15], mathematical problems of satellite information processing, the theory of tides [16], etc.

Currently, the most universal and promising technology for solving problems of the environment state monitoring and analyzing is the use of adjoint equations, optimal control methods $[1,10,11]$ and four-dimensional variational assimilation of observational data [8, 17]. The application of four-dimensional variational assimilation (4D-Var) and the use of more frequent observational data can improve the accuracy of short-term forecast [18]. The principle of four-dimensional variational assimilation usually implies that the forecast model is "ideal" within the assimilation window [19]. Such an approach selects the model trajectory that fits the observational data in the best way. The method of data assimilation $4 D$-Var has been introduced over the past few years in various centers of numerical weather prediction with significant advantages [20, 21]. However, all numerical models are imperfect, and the next step to solve problems of modeling marine environments and constructing effective assimilation algorithms was to consider bias observation errors, correlations of observation errors and model errors in a weak formulation of four-dimensional variational assimilation [22-24] and construction of covariance matrices of observation errors and their inclusion in the original cost function [5].

The present study examines a mathematical model of the general circulation of the Black and Azov seas with the procedure of variational assimilation of data on sea surface temperature, taking into account the covariance matrix of observation errors. Based on the variational assimilation of observational data, an algorithm 
for solving the inverse problem of restoring heat fluxes on the sea surface is proposed. The numerical model of the hydrothermodynamics of the Black and Azov seas, the Institute of Numerical Mathematics Ocean Model (INMOM), developed at the INM RAS [25], is adopted as a basis for the numerical implementation of the general sea circulation model. It also includes tidal potential recording in accordance with a special technique described in [26], where variational assimilation of annual average level observation data is used in calculating secondary tidal forces.

In the present paper, in contrast to $[10,26]$, the covariance matrix of observation errors calculated based on the statistical properties of the observation data for 1982-2017 is introduced into the functional. In addition, the daily average satellite observations of sea surface temperature for 2017 were taken as the assimilated data. When modeling the Black Sea dynamics, the dependence of other modeling parameters on the sea surface temperature assimilation were also studied in the present work.

\section{Mathematical model of the Black Sea dynamics}

Mathematical model of the Black Sea dynamics is considered in geographical coordinates. Assume that $\vec{U}=(u, v, w)$ is the velocity vector, $\zeta$ is the level function, $T$ is temperature, $S$ is salinity.

We write in the domain $D$ in variables $(x, y, z)$ when $t \in(0, \bar{t})$ system of equations of hydrothermodynamics for functions $u, v, \zeta, T, S$ in the Boussinesq and hydrostatics approximation [27], with Lame coefficients for a spherical coordinate system [28]:

$$
\left\{\begin{array}{c}
\frac{d \vec{u}}{d t}+\left[\begin{array}{cc}
0 & -f \\
f & 0
\end{array}\right] \vec{u}-g \operatorname{grad} \zeta+A_{u} \vec{u}+\left(A_{k}\right)^{2} \vec{u}=\vec{f}-\frac{1}{\rho_{0}} \operatorname{grad} P_{a}- \\
-\frac{g}{\rho_{0}} \operatorname{grad} \int_{0}^{z} \rho_{1}(T, S) d z^{\prime}, \\
\frac{\partial \zeta}{\partial t}-m \frac{\partial}{\partial x}\left(\int_{0}^{H} \Theta(z) u d z\right)-m \frac{\partial}{\partial y}\left(\int_{0}^{H} \Theta(z) \frac{n}{m} v d z\right)=f_{3}, \\
\frac{d T}{d t}+A_{T} T=f_{T}, \quad \frac{d S}{d t}+A_{S} S=f_{S},
\end{array}\right.
$$

where $\vec{u}=(u, v) ; \quad \rho_{1}(T, S)=\rho_{0} \beta_{T}\left(T-T^{(0)}\right)+\rho_{0} \beta_{S}\left(S-S^{(0)}\right)+\gamma \rho_{0} \beta_{T S}(T, S)+f_{P}$, $\vec{f}=\left(f_{1}, f_{2}\right), \quad f_{T}, f_{S}, f_{P}, \quad \rho_{0}, T^{(0)}, S^{(0)}, \quad \beta_{T S}(T, S), \quad P_{a}, \quad f_{3} \equiv f_{3}(x, y, t) \quad$ are prescribed functions, $\beta_{T}, \beta_{S}, \gamma=$ const; $A_{\varphi} \varphi \equiv-\operatorname{div}\left(\hat{a}_{\varphi} \operatorname{grad} \varphi\right)$, where index $\varphi$ can take values of $u, T, S ; g=$ const $>0, \Theta(z) \equiv \frac{R-z}{R} \approx 1$, where $R$ is Earth radius.

For the system (1) in $D \times(0, \bar{t})$ the following boundary and initial conditions are set [28] on the sea surface $\Gamma_{S}=\Omega$ : 


$$
\left\{\begin{array}{c}
\left(\int_{0}^{H} \Theta \vec{u} d z\right) \vec{n}+\beta_{0} m_{o p} \sqrt{g H} \zeta=m_{o p} \sqrt{g H} d_{s} \text { at } \Omega, \partial \\
U_{n}^{(-)} u-v \frac{\partial u}{\partial z}-k_{33} \frac{\partial}{\partial z} A_{k} u=\tau_{x}^{(a)} \rho_{0}, U_{n}^{(-)} v-v \frac{\partial v}{\partial z}-k_{33} \frac{\partial}{\partial z} A_{k} v=\tau_{y}^{(a)} \rho_{0}, \\
A_{k} u=0, \quad A_{k} v=0 \\
U_{n}^{(-)} T-v_{T} \frac{\partial T}{\partial z}+\gamma_{T}\left(T-T_{a}\right)=Q_{T}+U_{n}^{(-)} d_{T}, \\
U_{n}^{(-)} S-v_{S} \frac{\partial S}{\partial z}+\gamma_{S}\left(S-S_{a}\right)=Q_{S}+U_{n}^{(-)} d_{S},
\end{array}\right.
$$

where $\tau_{x}^{(a)}, \tau_{y}^{(a)}, \gamma_{T}, \gamma_{S}, T_{a}, S_{a}, Q_{T}, Q_{S}, d_{T}, d_{S}$ are prescribed functions; $U_{n}=U N$ ( $N$ is an external normal vector to the corresponding boundary), $U_{n}^{(-)}=\left(\left|U_{n}\right|-U_{n}\right) / 2,\left.\quad U_{n}\right|_{z=0}=-\left.w\right|_{z=0}$, and $\quad w=w(u, v)$ is introduced by the following formula

$$
w(x, y, z, t)=\frac{1}{r}\left(m \frac{\partial}{\partial x}\left(\int_{z}^{H} r u d z^{\prime}\right)+m \frac{\partial}{\partial y}\left(\frac{n}{m} \int_{z}^{H} r v d z^{\prime}\right)\right), \quad(x, y, t) \in \Omega \times(0, \bar{t}) .
$$

In addition, boundary conditions on the solid side wall $\Gamma_{w, c}$, on the liquid side wall $\Gamma_{w, o p}$ and at the bottom $\Gamma_{H}[26]$ are set.

The initial conditions for $u, v, T, S, \zeta$ have the following form:

$$
u=u^{0}, v=v^{0}, T=T^{0}, S=S^{0}, \zeta=\zeta^{0} \text { at } t=0,
$$

where $u^{0}, v^{0}, T^{0}, S^{0}, \zeta^{0}$ are prescribed functions.

The problem of large-scale sea dynamics in terms of $u, v, \zeta, T, S$ functions is formulated as follows: find $u, v, \zeta, T, S$, satisfying (1) - (4). If the functions $u, v, \zeta, T, S$ are found, then the function $w$ is determined by formula (3).

Note that the boundary conditions above can be modified depending on the specific physical problem. Problem (1) - (4) is approximated by the splitting method using the finite difference method [28, 29].

\section{The splitting method and the main features of the numerical model}

The main features of the numerical model of the Black Sea dynamics (1) - (4) are the simultaneous use of the splitting method [29, 30] and the transition to a $\sigma$ coordinate system.

Let a grid $0=t_{0}<t_{1}<\ldots<t_{j-1}<t_{j}=\bar{t}, \Delta t_{j}=t_{j}-t_{j-1}$ be introduced in $[0 ; \bar{t}]$ grid and consider problem (1) - (4) on $\left(t_{j-1}, t_{j}\right)$, taking in account that the approximate solution vector $\phi_{k} \equiv\left(u_{k}, v_{k}, \zeta_{k}, T_{k}, S_{k}\right), \quad k=1,2, \ldots, j-1$, has already been defined at the previous intervals. To approximate the problem, one of the total approximation method schemes [30, 31] is applied. It consists in 
implementing the following steps (to simplify the notation, the index $j$ for all components of the solutions of subproblems is omitted at these steps).

STEP 1. Problem of the following form is considered

$$
T_{t}+(\bar{U}, \operatorname{grad}) T-\operatorname{div}\left(\hat{a}_{T} \cdot \operatorname{grad} T\right)=f_{T} \text { in } D \times\left(t_{j-1}, t_{j}\right)
$$

under the corresponding boundary and initial conditions.

STEP 2. The problem

$$
S_{t}+(\bar{U}, \operatorname{grad}) S-\operatorname{div}\left(\hat{a}_{S} \cdot \operatorname{grad} S\right)=f_{S} \text { in } D \times\left(t_{j-1}, t_{j}\right)
$$

is solved under the corresponding boundary and initial conditions.

STEP 3. First, the system

$$
\left\{\begin{array}{l}
\underline{u}_{t}^{(1)}+\left[\begin{array}{cc}
0 & -\ell \\
\ell & 0
\end{array}\right] \underline{u}^{(1)}-g \operatorname{grad} \zeta=g \operatorname{grad} G-\frac{1}{\rho_{0}} \operatorname{grad}\left(P_{a}+g \int_{0}^{z} \rho_{1}(\bar{T}, \bar{S}) d z^{\prime}\right) \\
\operatorname{in} D \times\left(t_{j-1}, t_{j}\right), \\
\zeta_{t}-\operatorname{div}\left(\int_{0}^{H} \Theta \underline{u}^{(1)} d z\right)=f_{3} \text { in } \Omega \times\left(t_{j-1}, t_{j}\right), \\
\underline{u}^{(1)}=\underline{u}_{j-1}, \zeta=\zeta_{j-1} \text { at } t=t_{j-1}, \quad \underline{u}_{j}^{(1)} \equiv \underline{u}^{(1)}\left(t_{j}\right) \text { in } D
\end{array}\right.
$$

is solved with the corresponding boundary conditions and the function $\zeta_{j} \equiv \zeta^{(1)}$ is taken as an approximation to $\zeta$ at $\left(t_{j-1}, t_{j}\right)$, then the following problem is solved

$$
\begin{gathered}
\left\{\begin{array}{l}
\underline{u}_{t}^{(2)}+\left[\begin{array}{cc}
0 & -f_{1}(\bar{u}) \\
f_{1}(\bar{u}) & 0
\end{array}\right] \underline{u}^{(2)}=0 \text { in } D \times\left(t_{j-1}, t_{j}\right), \\
\underline{u}^{(2)}=\underline{u}_{j}^{(1)} \text { at } t=t_{j-1}, \quad \underline{u}_{j}^{(2)} \equiv \underline{u}^{(2)}\left(t_{j}\right) \text { in } D,
\end{array}\right. \\
\left\{\begin{array}{l}
\underline{u}_{t}^{(3)}+(\bar{U}, \operatorname{grad}) \underline{u}^{(3)}-\operatorname{div}\left(\hat{a}_{u} \cdot \operatorname{grad}\right) \underline{u}^{(3)}+\left(A_{k}\right)^{2} \underline{u}^{(3)}=0 \text { in } D \times\left(t_{j-1}, t_{j}\right), \\
\underline{u}^{(3)}=\underline{u}^{(2)} \text { at } t=t_{j-1} \text { in } D,
\end{array}\right.
\end{gathered}
$$

where $u^{(3)}=\left(u^{(3)}, v^{(3)}\right)$. After solving (9) the vector $u^{(3)} \equiv u_{j} \equiv\left(u_{j}, v_{j}\right)$ is taken as an approximation to the exact vector $u$ on $D \times\left(t_{j-1}, t_{j}\right)$ and the approximation $w_{j} \equiv w\left(u_{j}, v_{j}\right)$ is calculated to the vertical component of the velocity vector.

Thus, when the steps 1-3 are implemented, after the first step the approximation to $T$ is obtained, after the second - to $S$, after the third the approximation to $\underline{u}=(u, v)$, $\zeta$, i.e., the subproblems at these steps are independent of each other and can be solved in parallel.

Another feature of the numerical solution of the complete problem (1) - (4) is the use of the $\sigma$-coordinate system. The transition to the $\sigma$-system can be carried out at the stage of considering the complete problem before applying suitable splitting schemes and other numerical procedures [29]. However, the transition to PHYSICAL OCEANOGRAPHY VOL. 26 ISS. 6 (2019) 
$\sigma$-systems is also possible after applying splitting schemes, i.e., in the present case, as applied to problem (5) - (9). A number of other approaches to numerically solving problem (5) - (9) are described, for example, in [27, 29].

\section{The problem of variational assimilation of surface temperature data}

Assume that an observational data function $T_{o b s}$ be given at $\bar{\Omega} \equiv \Omega \cup \partial \Omega$ when $t \in\left(t_{j-1}, t_{j}\right), j=1,2, \ldots, J$, which in its physical sense is an approximation to the function of the sea surface temperature (SST) on $\Omega$, i.e. to $\left.T\right|_{z=0}$. The case when $T_{o b s}$ is found only on a subset of $\Omega \times(0, \bar{t})$, the support of which is denoted by $m_{0}$, is allowed. Since for numerical experiments, the daily average data was used as $T_{o b s}$, then by the mean-value theorem there is at least one point $t_{j_{k}}$, value of $T_{o b s}$, in which it is close to the daily average value for the $\mathrm{k}^{\text {th }}$ day. Then, knowing the points $\left\{t_{j_{k}}\right\}, k=1, \ldots, K$, for the assimilation procedure, the characteristic function $m_{0}$ in the following form can be used

$$
m_{0}=\left\{\begin{array}{c}
1, \quad \text { if } t \in \cup_{k=1}^{K}\left(t_{j_{k}-1}, t_{j_{k}}\right), \\
0, \text { otherwise. }
\end{array}\right.
$$

Also, by means of $m^{(j)}$ the function, determining the availability of observational data in a given time period $\left(t_{j-1}, t_{j}\right)$ is denoted. It is further assumed that the observational data is given with errors, namely:

$$
T_{\text {obs }}=\left.m_{0} T^{t}\right|_{z=0}+\xi_{\text {obs }},
$$

where $T^{t}$ is the exact solution of problem (5) where $Q=Q^{t}$, and $\xi_{\text {obs }} \in Y_{\text {obs }}=L_{2}(\Omega \times(0, \bar{t}))$ can be considered as an observation error. It is also assumed that errors $\xi_{\text {obs }}$ are random and distributed according to the normal law (Gaussian function) with zero mathematical expectation and a covariance operator $R \cdot=E\left[\left(\cdot, \xi_{o b s}\right) \xi_{o b s}\right], R: Y_{o b s} \rightarrow Y_{o b s}$, where $E$ is the expected value. It is further assumed that $R$ is positive definite and, therefore, reversible.

Assume that the additional unknown (control) is the total flux function $Q=-v_{t} \frac{\partial T}{\partial z}$ at $\Gamma_{s}$. The cost functional of the following form is introduced:

$$
\begin{aligned}
& J_{\alpha}(Q)=\frac{\alpha}{2} \int_{0}^{\bar{t}} \int_{\Omega}\left|Q-Q^{(0)}\right|^{2} d \Omega d t+\frac{1}{2} \sum_{j=1}^{J} J_{0, j}, \\
& J_{0, j} \equiv \int_{t_{j-1}} \int_{j}\left(\left.m_{0} T\right|_{z=0}-T_{\mathrm{obs}}\right) R^{-1}\left(\left.m_{0} T\right|_{z=0}-T_{\mathrm{obs}}\right) d \Omega d t,
\end{aligned}
$$

where $Q^{(0)}=Q^{(0)}(x, y, t)$ is the prescribed function; $\alpha=$ const $>0$ is the regularization parameter.

The problem of variational assimilation is formulated as follows: find a solution $\phi$ and a function $Q$, such that the functional (10) takes the least value. 
As shown in [10], the optimality system that determines the solution of the formulated problem of variational data assimilation, according to the necessary condition grad $J_{\alpha}=0$, is reduced to the sequential solution of the direct and adjoint equations and an additional expression for control $t \in\left(t_{j-1}, t_{j}\right), \quad j=1,2, \ldots, J$. The issues of unique and dense solvability of the problem were considered in [10, 32] .

Some of the algorithms for solving the problem under consideration by the example of the interval $\left(t_{0}, t_{1}\right)$ should be formulated. Construction of approximate solutions of the complete numerical model with the simultaneous determination of $Q$ by the variational assimilation procedure can be carried out by the following iterative algorithm: if $Q^{(k)}$ is an already constructed approximation to $Q$, then after solving the direct problem under $Q \equiv Q^{(k)}$, the corresponding adjoint problem is solved, and then the following approximation $Q^{(k+1)}$ is determined:

$$
Q^{(k+1)}=Q^{(k)}-\gamma_{k}\left(\alpha\left(Q^{(k)}-Q^{(0)}\right)+T^{*}\right) \quad \text { on } \Omega \times\left(t_{0}, t_{1}\right)
$$

With the parameter $\gamma_{k}$, which is chosen so that the iterative process considered is convergent [10]. Here $T^{*}$ is the corresponding adjoint problem solution. After $Q^{(k+1)}$ determination, the solution of direct and adjoint problems is repeated with a new approximation $Q^{(k+1)}$, and then $Q^{(k+2)}$ is calculated, etc. Iterations are repeated until a suitable convergence criterion is met.

Due to the property of dense solvability as $\left\{\gamma_{k}\right\}$ parameters can be selected parameters calculated by the formula for $\alpha \approx+0$ [10]:

$$
\gamma_{k}=\frac{1}{2} \int_{t_{0} \Omega}^{t_{1}} \int\left(\left.m_{0} T\right|_{z=0}-T_{\text {obs }}\right) R^{-1}\left(\left.m_{0} T\right|_{z=0}-T_{\text {obs }}\right) d \Omega d t /\left.\int_{t_{0} \Omega}^{t_{1}} \int\left(T_{2}^{*}\right)^{2}\right|_{z=0} d \Omega d t,
$$

which can significantly accelerate the convergence of the iterative process.

The problem above belongs to the class of four-dimensional variational assimilation problems. The splitting method is considered here as a method of approximating the original model, while the problem of variational assimilation itself is solved on the set $D \times\left(t_{0}, t_{1}\right)$ (or on $D \times\left(t_{j-1}, t_{j}\right), j>1$ ).

\section{Results of the numerical experiments}

For numerical experiments, the three-dimensional model of hydrothermodynamics of the Black and Azov seas developed at the INM RAS $[25,26]$ was used. The model is supplemented by the afore-described of sea surface temperature assimilation block. The parameters of the computational domain and its geographical coordinates were set with the following characteristics: $\sigma$-grid of $286 \times 159 \times 27$ points (in latitude, longitude and depth, respectively). The first point of the C-grid is a point with coordinates of $27.475^{\circ} \mathrm{E}$, $40.93^{\circ} \mathrm{N}$. The grid steps along $x$ and $y$ are constant and equal to $0.05^{\circ}$ and $0.04^{\circ}$, respectively. Time step $\Delta \mathrm{t}=5 \mathrm{~min}$. The calculations were carried out with the regularization parameter $\alpha=10^{-6}$. 
As the observational data $T_{o b s}$, the daily average satellite data on the Black Sea surface temperature for 2017 were used [33], which were verified and interpolated to the computational grid of the numerical model [34, 35]. As $Q^{(0)}$ the flux obtained from the reanalysis data of the National Center for Environmental Prediction (NCEP) for 2017 was used. An example of observational data assimilated in numerical experiments is shown in Fig. 1.

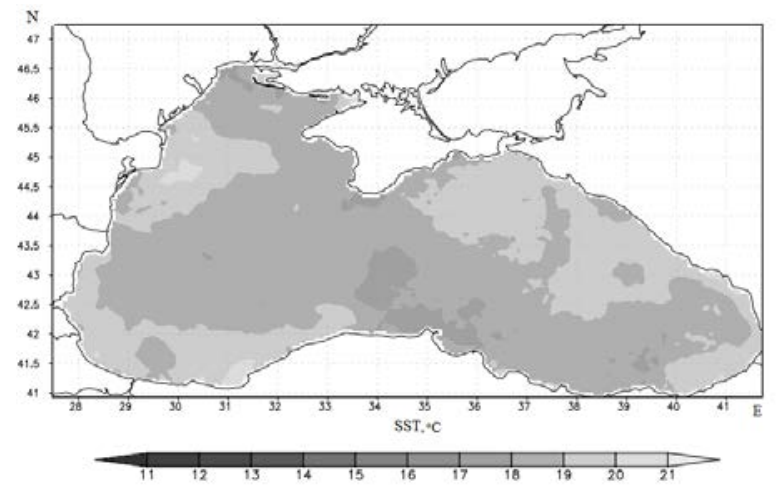

F i g. 1. The Black Sea surface temperature $\left({ }^{\circ} \mathrm{C}\right)$, mean daily observations, June 3, 2017

Based on the indicated daily average SST data for 1982-2017 the statistical mean and standard deviation are calculated. These statistical characteristics are used as coefficients in the covariance matrices of observation errors, the inverse of which are included as weight operators in the original cost functional in solving the variational data assimilation problem [36].

By means of the numerical sea hydrothermodynamics model presented, supplemented by the surface temperature assimilation procedure, calculations for the Black and Azov seas were carried out, taking into account the assimilation procedure. The calculation included the sea surface temperature assimilation $T_{o b s}$ for up to 3 days. Experiments were carried out for June 2017 (the beginning period is the first day of the month). As an external influence for the dynamics model of the Black and Azov seas, real ERA-Interim data presented by the European Center for Medium-Range Weather Forecasts (ECMWF) for 2017 were used.

Below some results of numerical experiments are shown. The results of the calculation using the numerical model of hydrothermodynamics without the assimilation procedure are presented in Fig. 2, $a$, where the average sea surface temperature is shown on the third day of calculation (June 3). The result of a similar calculation with the assimilation procedure is shown in Fig. 2, b. A comparison of the results shows that the model somewhat overestimates the SST in the southwestern Black Sea, however, the use of assimilation reduces the discrepancy. In the Azov Sea, the SST values are identical in both cases due to the lack of calculation of observational data in this region during the indicated period. 

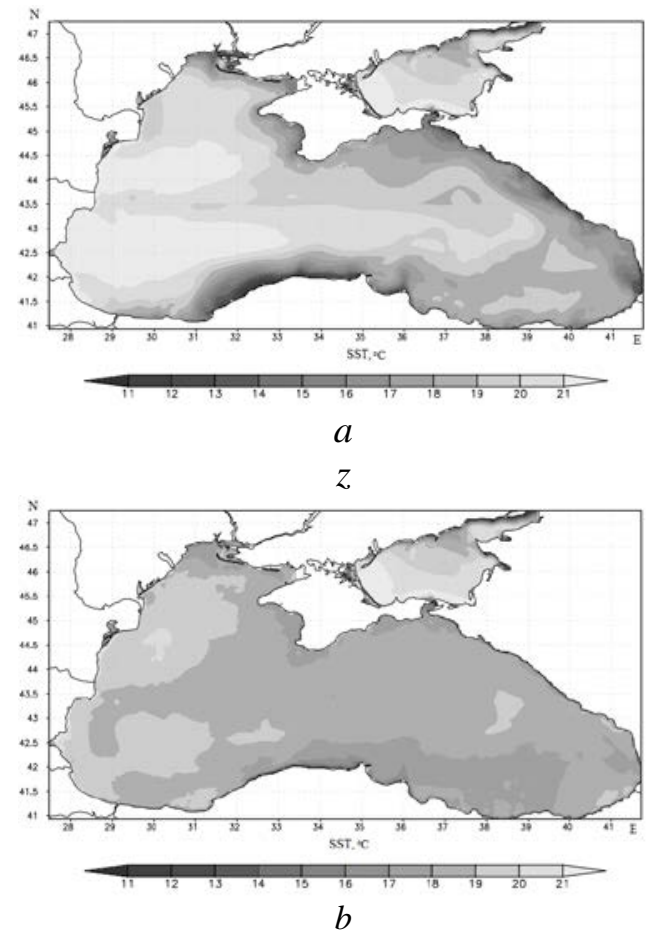

F i g. 2. SST of the Black and Azov seas $\left({ }^{\circ} \mathrm{C}\right)$, June 3, 2017. $a$ - model calculation without assimilation procedure, $b$ - model calculation using the assimilation procedure

Fig. 3 shows the difference between the SST calculated for this experiment (Fig. 2, b) and the observational data (Fig. 1). It can be seen from the comparison that the surface temperature assimilation in the numerical model permits to reduce the model solution deviation from the observational data $T_{o b s}$ for the calculation period. The use of variational assimilation algorithms can reduce the indicated deviation in some areas of the Black Sea by up to $2^{\circ} \mathrm{C}$.

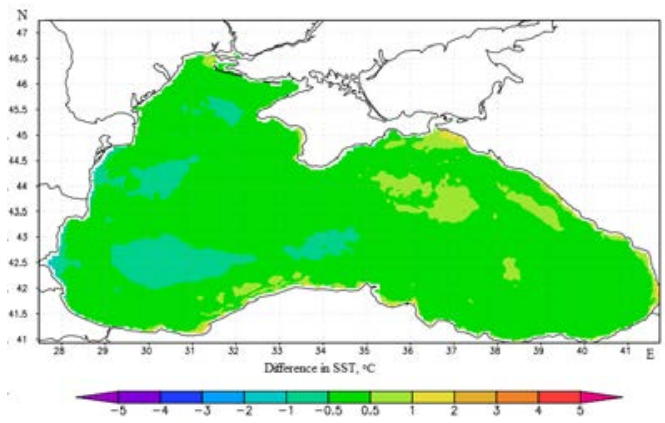

F i g. 3. Difference between the SST mean value resulted from the model calculation with the SST data assimilation procedure and that obtained from the observation data, June 3, 2017

Influence of the SST assimilation process on other system parameters was also studied in the present work. Fig. 4 shows the difference between salinity at the sea surface during the SST assimilation and without assimilation. Based on PHYSICAL OCEANOGRAPHY VOL. 26 ISS. 6 (2019) 
the calculation results, it can be concluded that the SST assimilation has a small effect on salinity at the sea surface (the variation doesn't exceed $0.2 \%$ o).

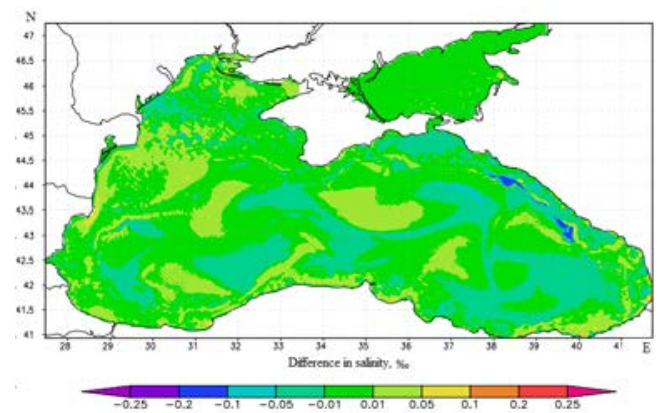

F i g. 4. Difference between the surface salinity (\%) resulted from the model calculation with the SST data assimilation procedure and that obtained without the SST data assimilation procedure, June 3, 2017

Fig. 5 shows the difference between the velocity field on the Black Sea surface, calculated by a numerical model with the SST data assimilation procedure and without including the assimilation procedure. Here, the small effect of the SST assimilation procedure on water circulation on the surface of the Black Sea (up to $7 \mathrm{~cm} / \mathrm{s}$ ) can be noted.

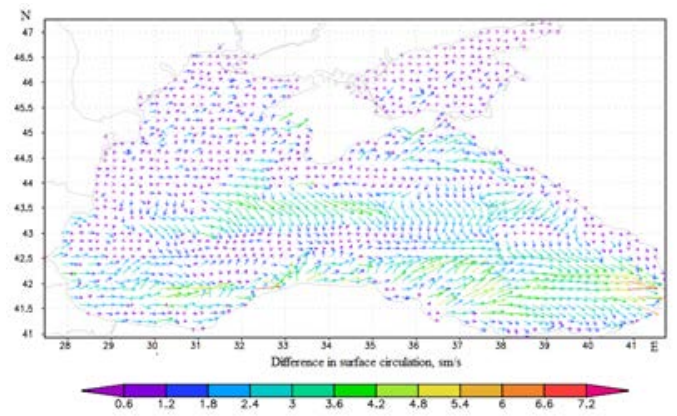

F i g. 5. Difference between the surface circulation velocities $(\mathrm{cm} / \mathrm{sec})$ resulted from the model calculation with the SST data assimilation procedure and that obtained without the SST data assimilation procedure, June 3, 2017

The SST assimilation procedure effect on the sea surface level in the numerical experiments was not observed.

\section{Conclusion}

The present paper considers the problem of numerical modeling of the hydrothermodynamics of the Black and Azov seas using variational assimilation procedures of average daily observations on the surface temperature of the Black Sea. The results of numerical calculations demonstrated the advantages of the numerical model using data assimilation procedures. One of the features of the developed model is the use of the splitting method, which permits to expand the application of assimilation procedures for the salinity and level function (in the presence of relevant observational data), since the steps are implemented independently. 
The study shows that the model solution becomes much closer to the observational data when using data assimilation procedures. The data assimilation also permits to take into account anomalies in sea surface temperature, which is not always possible to do when calculating by a numerical model without taking into account observational data.

Numerical calculations showed that the surface temperature assimilation procedure has a weak effect on other components of the complete solution of the problem - salinity, level and velocity functions. However, it is worth noting that the inclusion of tidal forces in the model has a significant effect on the parameters of the system.

\section{REFERENCES}

1. Marchuk, G.I., Paton, B.E., Korotaev, G.K. and Zalesny, V.B., 2013. Data-Computing Technologies: A New Stage in the Development of Operational Oceanography. Izvestiya, Atmospheric and Oceanic Physics, [e-journal] 49(6), pp. 579-591. https://doi.org/10.1134/S000143381306011X

2. Marchuk, G.I. and Paton, B.E., 2012. The Black Sea as a Simulation Ocean Model. Russian Journal of Numerical Analysis and Mathematical Modelling, [e-journal] 27(1), pp. 1-4. doi:10.1515/rnam-2012-0001

3. Le Dimet, F.X. and Talagrand, O., 1986. Variational Algorithms for Analysis and Assimilation of Meteorological Observations: Theoretical Aspects. Tellus A: Dynamic Meteorology and Oceanography, [e-journal] 38(2), pp. 97-110. https://doi.org/10.3402/tellusa.v38i2.11706

4. Ivanov, V.A., 2014. Spatial and Temporal Variability and Monitoring of Hydrophysical Fields of the Black Sea. Izvestiya, Atmospheric and Oceanic Physics, [e-journal] 50(1), pp. 26-34. https://doi.org/10.1134/S000143381306008X

5. Mogensen, K., Alonso-Balmaseda, M., Weaver, A., Martin, M. and Vidard, A., 2009. NEMOVAR: A Variational Data Assimilation System for the NEMO Ocean Model. Shinfield Park, England: ECMWF, 8 p. doi:10.21957/3yj3mh16iq

6. Talagrand, O., 2010. Variational Assimilation. In: W. Lahoz, B. Khattatov and R. Menard eds., 2010. Data Assimilation. Berlin, Heidelberg: Springer, pp. 41-67. doi:10.1007/978-3540-74703-1

7. Auroux, D. and Blum, J., 2005. Data Assimilation Methods for an Oceanographic Problem. In: V. Capasso, J. Périaux eds., 2005. Multidisciplinary Methods for Analysis Optimization and Control of Complex Systems. Mathematics in Industry (The European Consortium for Mathematics in Industry), vol. 6. Berlin, Heidelberg: Springer, pp. 180-194. doi:10.1007/3- 540-27167-8_4

8. Knysh, V.V., Demyshev, S.G., Korotaev, G.K. and Sarkisyan, A.S., 2007. Method and Results of Assimilation of Climatic Data on Temperature, Salinity, and Sea Level into a Numerical Model of the Black. Izvestiya, Atmospheric and Oceanic Physics, [e-journal] 43(3), pp. 363-377. https://doi.org/10.1134/S0001433807030115

9. Korotaev, G.K., Knysh, V.V., Lishaev, P.N. and Demyshev, S.G., 2018. Application of the Adaptive Statistics Method for Reanalysis of the Black Sea Fields Including Assimilation of the Temperature and Salinity Pseudo-measurements in the Model. Physical Oceanography, [e-journal] 25(1), pp. 36-51. doi:10.22449/1573-160X-2018-1-36-51

10. Agoshkov, V.I., 2003. Methods of Optimal Control and Adjoint Equations in Problems of Mathematical Physics. Moscow: INM RAS, 255 p. (in Russian).

11. Lions, J.L., 1968. Contrôle Optimal des Systèmes Gouvernés par des Équations aux Dérivées Partielles. Paris: Dunod Gauthier-Villars, 426 p.

12. Marchuk, G.I., 1995. Adjoint Equations and Analysis of Complex Systems. Dordrecht: Springer, 468 p. doi:10.1007/978-94-017-0621-6

13. Marchuk, G.I., 1974. Numerical Methods in Weather Prediction. New York: Academic Press, 288 p.

14. Marchuk, G.I., Agoshkov, V.I., Shutyaev, V.P., 1996. Adjoint Equations and Perturbation Algorithms in Nonlinear Problems. New York: CRC Press Inc., 288 p.

15. Marchuk, G.I., Dymnikov, V.P., Zalesny, V.B., Lykossov, V. and Galin, V.Ya, 1984. Mathematical Modeling of the General Circulation of the Atmosphere and Ocean. Leningrad: Gidrometeoizdat, 320 p. (in Russian). 
16. Marchuk, G.I. and Kagan, B.A., 1989. Dynamics of Ocean Tides. Dordrecht: Kluwer Academic Publishers, 327 p.

17. Zalesny, V.B., Zakharova, N.B., Gusev, A.V., 2011. Four-Dimensional Problem of Variational Initialization of Hydrophysical Fields of the World Ocean. Russian Journal of Numerical Analysis and Mathematical Modelling, [e-journal] 26(2), pp. 209-229. doi:10.1515/RJNAMM.2011.012

18. Järvinen, H., Andersson, E. and Bouttier, F., 1999. Variational Assimilation of Time Sequences of Surface Observations with Serially Correlated Errors. Tellus A: Dynamic Meteorology and Oceanography, [e-journal] 51(4), pp. 469-488. doi:10.3402/tellusa.v51i4.13963

19. Le Dimet, F.X., Navon, I.M. and Stefănescu, R., 2017. Variational Data Assimilation: Optimization and Optimal Control. In: S. Park, L. Xu eds., 2017. Data Assimilation for Atmospheric, Oceanic and Hydrologic Applications (Vol. III). Cham: Springer, pp. 1-53. doi:10.1007/978-3-319-43415-5_1

20. Moore, A.M., Arango, H.G., Broquet, G., Powell, B.S., Weaver, A.T. and Zavala-Garay, J., 2011. The Regional Ocean Modeling System (ROMS) 4-dimensional Variational Data Assimilation Systems: Part I - System Overview and Formulation. Progress in Oceanography, [e-journal] 91(1), pp. 34-49. doi:10.1016/j.pocean.2011.05.004

21. Rabier, F., 2005. Overview of Global Data Assimilation Developments in Numerical Weather-Prediction Centres. Quarterly Journal of the Royal Meteorological Society, [ejournal] 131(613), pp. 3215-3233. doi:10.1256/qj.05.129

22. Trémolet, Y., 2007. Incremental 4D-Var Convergence Study. Tellus A: Dynamic Meteorology and Oceanography, [e-journal] 59(5), pp. 706-718. https://doi.org/10.1111/j.16000870.2007.00271.x

23. Trémolet, Y., 2008. Computation of Observation Sensitivity and Observation Impact in Incremental Variational Data Assimilation. Tellus A: Dynamic Meteorology and Oceanography, [e-journal] 60(5), pp. 964-978. doi:10.1111/j.1600-0870.2008.00349.x

24. Akella, S. and Navon, I.M., 2009. Different Approaches to Model Error Formulation in 4DVar: a Study with High-Resolution Advection Schemes. Tellus A: Dynamic Meteorology and Oceanography, [e-journal] 61(1), pp. 112-128. doi:10.1111/j.1600-0870.2007.00362.x

25. Zalesny, V.B., Diansky, N.A., Fomin, V.V., Moshonkin, S.N. and Demyshev, S.G., 2012. Numerical Model of the Circulation of the Black Sea and the Sea of Azov. Russian Journal of Numerical Analysis and Mathematical Modelling, [e-journal] 27(1), pp. 95-112. doi:10.1515/rnam-2012-0006

26. Agoshkov, V.I., Assovskii, M.V., Zalesny, V.B., Zakharova, N.B., Parmuzin, E.I. and Shutyaev, V.P., 2015. Variational Assimilation of Observation Data in the Mathematical Model of the Black Sea Taking into Account the Tide-Generating Forces. Russian Journal of Numerical Analysis and Mathematical Modelling, [e-journal] 30(3), pp. 129-142. https://doi.org/10.1515/rnam-2015-0013

27. Marchuk, G.I., Dymnikov, V.P. and Zalesny, V.B., 1987. Mathematical Models in Geophysical Hydrodynamics and Numerical Methods for Their Implementation. Leningrad: Gidrometeoizdat, 295 p. (in Russian).

28. Agoshkov, V.I., Gusev, A.V., Diansky, N.A. and Oleinikov, R.V., 2007. An Algorithm for the Solution of the Ocean Hydrothermodynamics Problem with Variational Assimilation of the Sea Level Function Data. Russian Journal of Numerical Analysis and Mathematical Modelling, [e-journal] 22(2), pp. 133-161. doi:10.1515/RJNAMM.2007.007

29. Marchuk, G.I., Rusakov, A.S., Zalesny, V.B. and Diansky, N.A., 2005. Splitting Numerical Technique with Application to the High Resolution Simulation of the Indian Ocean Circulation. Pure and Applied Geophysics, [e-journal] 162(8-9), pp. 1407-1429. doi:10.1007/s00024-005-2677-8

30. Marchuk, G.I., 1989. Methods of Computational Mathematics. Moscow: Nauka, 608 p. (in Russian).

31. Samarskii, A.A., 1977. Theory of Difference Schemes. Moscow: Nauka, 657 p. (in Russian).

32. Parmuzin, E.I. and Agoshkov, V.I., 2012. Numerical Solution of the Variational Assimilation Problem for Sea Surface Temperature in the Model of the Black Sea Dynamics. Russian Journal of Numerical Analysis and Mathematical Modelling, [e-journal] 27(1), pp. 69-94. doi:10.1515/rnam-2012-0005

33. Buongiorno Nardelli, B., Tronconi, C., Pisano, A. and Santoleri, R., 2013. High and UltraHigh Resolution Processing of Satellite Sea Surface Temperature Data over Southern 
European Seas in the Framework of MyOcean Project. Remote Sensing of Environment, [ejournal] 129, pp. 1-16. doi:10.1016/j.rse.2012.10.012

34. Zakharova, N.B., 2017. [Problems of Observational Data Processing in the Tasks of Mathematical Modeling of Marine Environments]. In: Applied Aspects of Geology, Geophysics and Geoecology Using Modern Information Technologies: Materials of 4th International Scientific and Practical Conference. Maikop: Izd-vo IP Kucherenko V.O., pp. 211-219.

35. Zakharova, N.B., 2016. Verification of the Sea Surface Temperature Observation Data. Current Problems in Remote Sensing of the Earth from Space, 13(3), pp. 106-113. doi:10.21046/2070-7401-2016-13-3-106-113 (in Russian).

36. Agoshkov, V.I., Parmuzin, E.I., Zakharova, N.B. and Shutyaev, V.P., 2018. Variational Assimilation with Covariance Matrices of Observation Data Errors for the Model of the Baltic Sea Dynamics. Russian Journal of Numerical Analysis and Mathematical Modelling, [ejournal] 33(3), pp. 149-160. doi:10.1515/rnam-2018-0013

About the authors:

Valeriy I. Agoshkov - Principal Research Associate, Marchuk Institute of Numerical Mathematics of the Russian Academy of Sciences (8 Gubkina st., Moscow, 119991, Russian Federation), Dr. Sci. (Phys.-Math.), Professor, ResearcherID: Q-4041-2016, agoshkov@inm.ras.ru

Victor P. Shutyaev - Academic Secretary, Marchuk Institute of Numerical Mathematics of the Russian Academy of Sciences (8 Gubkina st., Moscow, 119991, Russian Federation), Dr. Sci. (Phys.-Math.), Professor, ResearcherID: D-7972-2014, shutyaev@inm.ras.ru

Evgeniy I. Parmuzin - Senior Research Associate, Marchuk Institute of Numerical Mathematics of the Russian Academy of Sciences (8 Gubkina st., Moscow, 119991, Russian Federation), Ph. D. (Phys.-Math.), Assistant Professor, ResearcherID: R-5908-2016, eparmuzin@gmail.com

Natalia B. Zakharova - Senior Research Associate, Marchuk Institute of Numerical Mathematics of the Russian Academy of Sciences (8 Gubkina st., Moscow, 119991, Russian Federation), Ph. D. (Phys.-Math.), ResearcherID: G-6300-2014, zakharova_nb@inm.ras.ru

Tatiana O. Sheloput - Junior Research Associate, Marchuk Institute of Numerical Mathematics of the Russian Academy of Sciences (8 Gubkina st., Moscow, 119991, Russian Federation), postgraduate, ResearcherID: K-1052-2016, tanya_chel@list.ru

Natalia R. Lezina - Junior Research Associate, Marchuk Institute of Numerical Mathematics of the Russian Academy of Sciences (8 Gubkina st., Moscow, 119991, Russian Federation), postgraduate, ResearcherID: Q-3964-2016, lezina@phystech.edu

Contribution of the co-authors:

Valeriy I. Agoshkov - general scientific management of research; formulation of the goals and objectives of the study; analysis of the applied research methodology

Victor P. Shutyaev - formulation and statement of the problem; selection and justification of numerical methods for solving equations; critical analysis and revision of the text

Evgeniy I. Parmuzin - development of methods and experimental studies; processing and description of the results of the study; building tables, graphs, charts; qualitative and quantitative analysis of the results

Natalia B. Zakharova - selection and analysis of literature; data collection and systematization; preparation of the initial version of the text; qualitative analysis of the results and their interpretation

Tatiana O. Sheloput - analysis of materials in domestic and foreign sources according to research methods; development and debugging of a computer program for solving a problem

Natalia R. Lezina - correction of the mathematical model and calculations; editing and addition of the text of the paper

All the authors have read and approved the final manuscript.

The authors declare that they have no conflict of interest. 